\title{
DIAGNOSTIC ACCURACY OF TRIPLE ASSESSMENT IN PALPABLE BREAST LUMP
}

\section{Surgery}

\section{Dr. Sitesh Kumar Karn \\ M.B.B.S., M.S. (Gen. Surgery),Senior Resident, Department ofSurgery, Nalanda Medical College and Hospital (NMCH), Patna, Bihar.}

Dr. Ramesh Kumar M.B.B.S., M.S. (Gen. Surgery),Associate Professor, Department ofSurgery, Nalanda Ajai*

\section{Dr. Debarshi Jana A.J.C. Bose Road, Kolkata-700020, West Bengal, India.} Medical College and Hospital (NMCH), Patna, Bihar. *Corresponding Author

Young Scientist (DST) Institute of Post-Graduate Medical Education and Research,

\begin{abstract}
Background:Breast diseases constitute a heterogeneous group of lesions including developmental abnormalities,inflammatory lesions, epithelial and stromal proliferations, and neoplasms. With the use of clinical examination, mammography and fine needle aspiration cytology (FNAC), the diagnosis of a benign breast disease can be accomplished without surgery in the majority of patients. Combined use of these diagnostic procedures (Triple assessment) gives nearly the same degree of accuracy as excisional biopsy in patients with palpable breast diseases. Currently a combination of three tests, i.e. clinical examination, radiological imaging (mammography, ultrasonography) and pathology called as triple assessment test is used to accurately diagnose all palpable breast lumps. The Triple Test Score (TTS) was developed to help physicians interpret discordant triple test results. A three-point scale is used to score each component of the triple test $(1=$ benign, $2=$ suspicious, $3=$ malignant $)$. A TTS of 3 or 4 is consistent with a benign lesion; a TTS of 6 or more indicates possible malignancy that may require surgical intervention. Excisional biopsy is recommended in patients with a TTS of 5 to obtain a definitive diagnosis.

Materials and methods: The study was conducted for diagnostic accuracy of triple assessment in palpable breastlump in 50 patients. The components of the Triple Assessment are: Clinical examination (C/E), Mammography/ ultrasonograph and Fine Needle Aspiration Cytology (FNAC). The diagnostic accuracy of triple asseserment was reached by comparing the results of this test with gold standard i.e. histopathological findings.

Results : The TT was concordant in 46 cases (92\%). In 17 of these lesions (34\%), the results of TT were interpretedas benign and subsequently were proved to be benign pathologies histologically with NPV and Specificity of $100 \%$. Similarly, in 29 cases (58\%) the results of all elements of TT were interpreted as malignant, which proved to be malignant lesions on histopathological examination and the sensitivity and PPV were $100 \%$.TT elements were non concordant in 4 cases ( $8 \%$ ), 3 of these cases were proved to have malignant masses and the remaining 1 case was proved to be benign on subsequent histopathological examination. In all the non concordant cases, where at least one of the elements was considered benign, FNAC was the most accurate with 0 false negative and 0 false positive results.

Conclusion: The TT has proved to be accurate, reliable diagnostic approach for evaluation of breast masses, achieved(100\%) accuracy rate when all elements were concordant or when all elements were either suspicious or malignant. The study shows that when TT is concordant, final treatment may be ensued without open biopsy. In non-concordantcases, FNAC stands as single most important investigation. However due to its false negative results, other components of triple test need to be employed to enhance its efficacy and diagnostic yield.
\end{abstract}

\section{KEYWORDS}

palpable breast lump, triple assessment, triple test score

\section{INTRODUCTION}

Breast diseases, with its uncertain cause, have captured the attention of surgeons throughout the ages. Breast lump is a very sensitive issue for the patient so a reliable, non invasive and prompt diagnosis helps to lessen the associated anxiety and leads to early definitive treatment. The tools for clinical diagnosis i.e. history, clinical breastexamination, FNAC, and diagnostic mammography provide valuable information and play important supplemental roles in ascertaining the presence of breast cancer.

For patients who present to clinicians with palpable breast lesions, the triple test: (physical examination, mammography and fine-needle aspiration cytology) can be employed to provide accurate diagnosis ${ }^{5}$ The diagnostic value of aspiration cytology and the overall diagnostic quality of the so-called triple test (aspirationcytology, mammography and physical examination) helps in the evaluation of palpable breast masses. The triple test score (TTS) reliably guides evaluation and treatment of palpable breast masses.

Jane $M$ et al found that the sensitivity and specificity of all the modalities used in triple assessment when combined together was $100 \%$ and $99.3 \%$, respectively. The concordance for the triple assessment was $99.3 \%$, positive predictive value was $93.3 \%$, negative predictive value was $100 \%$, sensitivity was $100 \%$ and specificity was $99.3 \%$. p value was significant $(0.000)$.

Hider P et al in their study included 232 studies, of which 33 focused on evaluating diagnostic tools for identifying breast cancer ( 5 on fineneedle aspiration, 6 on the triple test, 6 on core biopsy and 7 on scintigraphic imaging). They concluded that triple testing with mammography, fine-needle aspiration and clinical examination is more accurate than any of the tests alone.

\section{MATERIALS AND METHODS}

The prospective cross sectional study was done in the Department of Surgery at Nalanda Medical College and Hospital, Patna, Bihar. The inclusion criteria were all female patients presenting in the Surgical OPD with a clinically palpable breast lump. These patients were subjected to triple assessment i.e. Step 1: Clinical assessment; Step 2: Mammography for patients aged more than 30 years and sonomammography for patients less than 30 years old; Step 3: FNAC.

The findings of these were graded by a scoring system as follows: Clinical examination:

1: Benign lump

2: Suspicious lump

3: Malignant lump

Ultrasonography(>30years)\&Sonomammography(<30years) :

1: Benign lump

2: Suspicious lump

3: Malignant lump

FNAC:

1: Benign lump

2: Suspicious lump

3: Malignant lump

This grading was further used to group the patients into benign, suspicious or malignant breast lumps. This final result was compared and co-related with the histopathological findings, and hence the diagnostic accuracy of triple assessment was assessed

\section{RESULTS}

Incidence of various lesions in relation to the histopathology reports 
In the present study, malignant breast disorders 32 ( $64 \%$ of the cases) accounted for majority of breast lumps in which, infiltrating ductal carcinoma had the lead with $29(90 \%)$ cases followed by 2 cases of invasive lobular carcinoma (6.25\%) and mucinous carcinoma of 1 case $(3.12 \%)$ only. Most common benign lesion was fibroadenoma constituting 7 cases (14\%) followed by 5 cases $(10 \%)$ of fibrocystic disease and then by 2 cases (4\%) of fibroadenosis. Only 1 case $(2 \%)$ each of inflammatory, intraductal papilloma, sclerosingadenosis and duct ectasia were found.

Table -1 : Incidence of various lesions in relation to the histopathology reports

\begin{tabular}{|l|l|l|}
\hline Types of lesions & No. of cases & Percentage (\%) \\
\hline Fibroadenoma & 7 & 14 \\
\hline Fibroadenosis & 2 & 4 \\
\hline Fibrocystic disease & 5 & 10 \\
\hline Inflammatory & 1 & 2 \\
\hline Intraductal papilloma & 1 & 2 \\
\hline Sclerosingadenosis & 1 & 2 \\
\hline Duct ectasia & 1 & 2 \\
\hline Infilterating ductal carcinoma (IDC) & 29 & 58 \\
\hline Invasive lobular carcinoma & 2 & 4 \\
\hline Mucinous carcinoma & 1 & 2 \\
\hline Total & 50 & 100 \\
\hline
\end{tabular}

Results of triple tests for (50) palpable breast lesions and histopathology confirmation

The TT was concordant in 46 cases $(92 \%)$. In 17 of these lesions (34\%), the results of TT were interpreted as benign and subsequently were proved to be benign pathologies histologically with NPV and Specificity of $100 \%$. Similarly, in 29 cases $(58 \%)$ the results of all elements of TT were interpreted as malignant, which proved to be malignant lesions on histopathological examination and the sensitivity and PPV were $100 \%$ TT elements were non concordant in 4 cases $(8 \%), 3$ of these cases were proved to have malignant masses and the remaining 1 case wasproved to be benign on subsequent histopathological. In all the non concordant cases, where at least one of the elements was considered benign, FNAC was the most accurate with 0 false negative and 0 false positive results. The detailed description of grading, triple test score and final diagnosis on histopathology of all concordant and non concordant cases is given in table 2 .

Table -2 :Results of triple tests for palpable breast lesions and histopathology confirmation

\begin{tabular}{|c|c|c|c|c|c|c|}
\hline \multirow[t]{2}{*}{ TT Results } & & \multirow[t]{2}{*}{$\begin{array}{l}\text { No. of } \\
\text { lesions }\end{array}$} & \multicolumn{2}{|c|}{$\begin{array}{c}\text { Histopathology } \\
\text { results }\end{array}$} & \multicolumn{2}{|c|}{ Total } \\
\hline & & & Benign & Malignant & No. & $\%$ \\
\hline \multirow[t]{2}{*}{ Concordant } & Benign & 17 & 17 & 0 & \begin{tabular}{|c|}
17 \\
\end{tabular} & 34 \\
\hline & Malignant & 29 & 0 & 29 & 29 & 58 \\
\hline Non concordant & Suspicious & 4 & 1 & 3 & 4 & 8 \\
\hline Total & & & 18 & 32 & 50 & 100 \\
\hline
\end{tabular}

True Positive -32

False positive -0

True Negative -18

False Negative -0

Sensitivity $-100 \%$

Specificity $-100 \%$

Positive Predictive Value- $100 \%$

Negative Predictive Value $-100 \%$

Accuracy $-100 \%$

Table -3 :Triple test score of concordant and non concordant cases

\begin{tabular}{|c|c|c|c|c|c|}
\hline $\begin{array}{c}\text { No. of } \\
\text { cases }\end{array}$ & $\begin{array}{c}\text { Clinical } \\
\text { Examination }\end{array}$ & Imaging & FNAC & TTS & Histopathology \\
\hline 17 & 1 & 1 & 1 & 3 & Benign \\
\hline 29 & 3 & 3 & 3 & 9 & Malignant \\
\hline 1 & 1 & 2 & 3 & 6 & IDC \\
\hline 1 & 1 & 2 & 3 & 6 & IDC \\
\hline 1 & 1 & 2 & 1 & 4 & FA \\
\hline 1 & 1 & 2 & 3 & 6 & IDC \\
\hline
\end{tabular}

\section{Analysis of triple test and its components}

FNAC was found to be the most accurate element of triple assessment in which sensitivity, specificity, positive predictive value, negative predictive value and accuracy were found to be $100 \%$. The sensitivity of clinical breast examination and imaging were found to be $90.6 \%$ and $96.9 \%$ respectively and negative predictive value was $85.71 \%$ and $94.4 \%$ respectively. Both clinical breast examination and imaging had the specificity and positive predictive value of $100 \%$ each

Table -4 :Analysis of triple test score (TTS) and its components for 50 cases of palpable breast lumps

\begin{tabular}{|c|c|c|c|c|}
\hline Measure & CBE & Imaging & FNAC & TTS \\
\hline \begin{tabular}{|l|} 
Sensitivity \\
\end{tabular} & 90.62 & 96.97 & 100 & 100 \\
\hline Specificity & 100 & 100 & 100 & 100 \\
\hline PPV & 100 & 100 & 100 & 100 \\
\hline NPV & 85.71 & 94.44 & 100 & 100 \\
\hline Accuracy & 94 & 98 & 100 & 100 \\
\hline
\end{tabular}

Figure 1 Showingpeau'd Orange

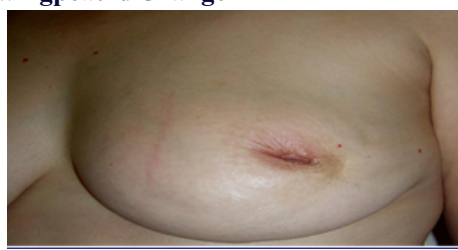

Figure 2 Showing Nipple Retraction

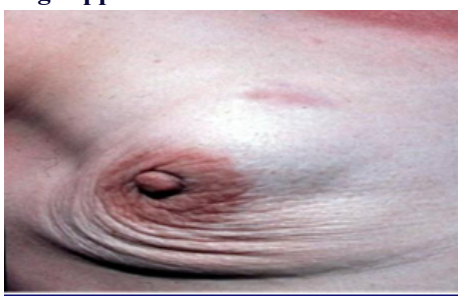

Figure 3 Showing Breast Lump And Nipple Deviation

\section{DISCUSSION}

The main objective of the present study was to become conversant with percentage of various types of breast disorders including both benign and malignant on the basis of clinical breast examination, imaging technology and fine needle aspiration cytology.

A total of 50 female patients presenting to the surgery department with breast lump were studied by all the three components of triple test. All the cases underwent lumpectomy/ quadrantectomy/ mastectomy for histopathological confirmation of diagnosis. The TT components (clinical breast examination, imaging technology, fine needle aspiration cytology) were categorized as benign, suspicious and malignant. Each component is designated as benign, suspicious and malignant and rated as 1,2 and 3 respectively. TTS is the sum of these scores with a minimum score of 3 (3-4; concordant benign) and a maximum score of 9 (6-7; concordant malignant), 5 having intermediate risk needing further evaluation before any definitive treatment.

TT was considered concordant when all three elements indicated benign or all three elements indicated malignant. The findings were correlated as triple assessment and compared with histopathology reports.

In the present study, malignant breast disorders $32(64 \%$ ofthe cases)accounted for majority ofbreast lumps in which, infilterating ductalcarcinoma had the lead with $29(90 \%)$ of totalmalignant cases followed by lobular carcinoma $2(6.25 \%)$ and mucinous carcinoma of 1 case $(3.12 \%)$ only

These findings are similar to the study of Khokher $\mathrm{S}$ et al in which infilterating ductal carcinoma was found in $91 \%$ of the total malignant cases followed by lobular carcinoma and then by mucinous carcinoma. 
Also in the study of Saleem KN, IDC was the most common malignant pathology and constituted ( $76 \%$ ) of all malignant masses followed by lobular carcinoma which formed $(12 \%)$. For benign masses, fibroadenoma was the predominant lesion, formed (28\%) of all benign masses followed by fibrocystic disease $(22.8 \%)$.

The TT was concordant in 46 cases $(92 \%)$. In 17 of these lesions (34\%), the results of TT were interpreted as benign and subsequently were proved to be benign pathologies histologically with NPV and Specificity of $100 \%$. Similarly, in 29 cases (58\%) in which the results of all elements of TT were interpreted as malignant, proved to be malignant lesions on histopathological examination and the sensitivity and PPV were $100 \%$ TT elements were non concordant in 4 cases $(8 \%), 3$ of these cases were proved to have malignant masses and the remaining 1 case wasproved to be benign on subsequent histopathological. In all the non concordant cases, where at least one of the elements was considered benign, FNAC was the most accurate with 0 false negative and 0 false positive results.

More or less similar results were seen in the study of Jan $\mathrm{M}$ et al in which the concordance for the triple assessment was $99.3 \%$, positive predictive value was $93.3 \%$, negative predictive value was $100 \%$, sensitivity was $100 \%$ and specificity was $99.3 \%$.

Also in the study of Nigam $\mathrm{M}$ et al the concordance for the triple assessment was $99.3 \%$, positive predictive value was $93.3 \%$, negative predictive value was $100 \%$, sensitivity was $100 \%$ and specificity was $99.3 \%$

The sensitvity, specifcity, positve predictive value, negative predictive value was found to be $100 \%$ in the study of Chalaya PLet al.

Also Saleem KN found FNAC to be the most reliable element of TT in cases where the elements of TT were non concordant.

Another study was done by Veto $\mathrm{J}$ et al in which all 21 cases where the triple test was concordant (elements had either all malignant or benign results), open biopsy was confirmatory (negative predictive value and sensitivity both $100 \%$ ). Fine-needle aspiration was the most reliable element of the triple test in cases where the elements of the test were non-concordant (negative predictive value and sensitivity of $95 \%$ and $96 \%$, respectively), followed by mammogram and then by physical examination

In the study of Nigam et al the sensitivity and specificity of all the modalities used in triple assessment when combined together was $100 \%$ and $99.3 \%$, respectively. The concordance for the triple assessment was $99.3 \%$, positive predictive value was $93.3 \%$, negative predictive value was $100 \%$, sensitivity was $100 \%$ and specificity was $99.3 \%$. p value was significant $(0.000)$

Sharma $\mathrm{P}$ et al in their study found that out of clinical breast examination, mammography and/or ultrasonography, and fine needle aspiration cytology, diagnostic accuracy of the latter was highest $(100 \%)$. The Triple Test Score had a diagnostic accuracy of $98.33 \%$ and sensitivity, specificity, positive predictive value and negative predictive value of $100 \%$ each. The Triple Test was correlated with biopsy reports and yielded comparable diagnostic accuracy.

Lingaraju $\mathrm{N}$ in their studyfound that triple assessment is a very useful diagnostic tool to evaluate patients with breast lumps and to detect patients with breast cancers with an overall accuracy of $99.3 \%$. When the lumps are palpable clinically and of size more than $2 \mathrm{~cm}$ fi neneedle aspiration cytology itself has a sensitivity of $100 \%$. The triple assessment did not require hospitalization, can be performed on OPD basis, without any complications and it is the gold standard diagnostic tool for the palpable breast lumps in early detection of malignancy avoiding biopsies.

\section{CONCLUSION}

The TT has proved to be accurate, reliable diagnostic approach for evaluation of breast masses, achieved (100\%) accuracy rate when all elements were concordant or when all elements were either suspicious or malignant. The study shows that when TT is concordant, final treatment may be ensued without open biopsy. In non-concordant cases, FNAC stands as single most important investigation. However due to its false negative results, other components of triple test need to be employed to enhance its efficacy and diagnostic yield.

\section{REFERENCES}

1. Al-Mulhim AS, Sultan M, Al-Mulhim FM, Al-Wehedy A, Ali AM, Al-Suwaigh A Accuracy of the "triple test" in the diagnosis of palpable breast masses in Saudi females. Ann Saudi Med. 2003;158-61. Breast Lesions and its Correlation with Histopathology, SJAMS 2016; 4(8D):3002-8

2. Chalaya PL, Lema MK, Mabula JB, Rambau P, Mchembe MD, Masalu N et al. Triple assesment as a preoperative diagnostic tool for breast cancer at Bugando Medical Centre in northwestern Tanzania. Tanzan J Health Res 2013; 15(4):223-9.

3. Ghimire B, Khan M, Bibhusal T, Singh Y, Savami P. Accuracy of triple test score in the diagnosis of palpable breast lump. J Nepal Med Assoc. 2008;189-92.

4. Hider P, Nicholas B. The early detection and diagnosis of breast cancer: a literature Hider P, Nicholas B. The early dete
review. NZHTA 1999; 2(2):252-8.

5. Jane M, Mattoo JA, Salroo NA, Ahangar S. Epub 2010 Jul 1. Triple assessment in the diagnosis of breast cancer in Kashmir. Indian J Surg 2010; 72(2): 97-103.

6. Kamphausen BH, Toellner T, Ruschenburg I. The value of ultrasound-guided fineneedle aspiration cytology of the breast: 354 cases with cytohistological correlation. Anticancer Res 2003; 23:3009-13.

7. Khokher S, Qureshi MU, Riaz M, Akhtar N, Saleem A. Clinicopathologic Profile of Breast Cancer Patients in Pakistan: Ten Years Data of a Local Cancer Hospital. Asian Pacific J Cancer Prev 2013; 13:693-9.

8. Lingaraju N, Narashimhaswamy P, Mohan RM, Venkatesh N. Evaluation of Palpable Breast Lumps under the Age of 35 Years with Triple Assessment. Int J Sci Stud 2016;4(1):10-15

9. Morris A, Pommier RF, Schmidt WA, Shih RL, Alexander PW, Vetto JT. Accurate evaluation of palpable breast masses by the triple test score. Arch Surg. 1998;133(9):930-4.

10. Nigam M, Brijender M. Triple Assessment of Breast - Gold Standard in Mass Screenin for Breast Cancer Diagnosis. IOSR May,2013; 7(3):01-07.

11. Saleem KN. Evaluation of Triple Assessment Modalities in the Management of Palpable Breast Lumps. IPMJ2010; 9(1): 48-56.

12. Sharma P, Tewari V, Sharma AK. Triple Test: A 'One Stop' Diagnostic Test in Evaluation of

13. Steinberg JL, Trudeau ME, Ryder DE, Fishell E, Chapman JA, McCready DR, et al Combined fine-needle aspiration, physical examination and mammography in the diagnosis of palpable breast masses: their relation to outcome for women with primary breast cancer. Can J Surg 1996; 39: 302-11.

14. Vargas HI, Anderson BO, Chopra R, Lehman CD, Ibarra JA, Masood S, et al. Diagnosis of Breast Cancer in Countries with Limited Resources. The Breast Journal. 2003:9:60-6. Vetto J, Pommier R, Schmidt W, Wachtel M, Du Bois P, Jones M et al. Use of the triple test for pappable breast lesions yields high diagnostic accuracy and cost savings. Am J Surg $1995 ; 169(5): 519-22$ 